\title{
Sedative and clinical effects of the pharmacopuncture with xylazine in $\operatorname{dog} s^{1}$
}

\author{
Renata Navarro Cassu', Alessandra Melchert" ${ }^{\mathrm{II}}$, Jiancarlo Tortoza Bignelli Canoa ${ }^{\mathrm{III}}$, Paula Denise de Oliveira Martins ${ }^{\mathrm{IV}}$ \\ ${ }^{\mathrm{I}} \mathrm{PhD}$, Full Professor, Department of Veterinary Surgery and Anestesiology, Scholl of Veterinary Medicine, Oeste Paulista University (UNOESTE), \\ Presidente Prudente-SP, Brazil. Intellectual and scientific content of the study, statistical analysis, manuscript writing, critical revision. \\ IIPhD, Full Professor, Department of Clinical Veterinary, Scholl of Veterinary Medicine, Sao Paulo State University (UNESP), Botucatu-SP, Brazil. \\ Technical procedures, acquisition and interpretation of data. \\ IIIMaster, Full Professor, Department of Veterinary Anestesiology, Scholl of Veterinary Medicine, Andradina Educational Foundation (FEA), Andradina- \\ SP, Brazil. Technical procedures.

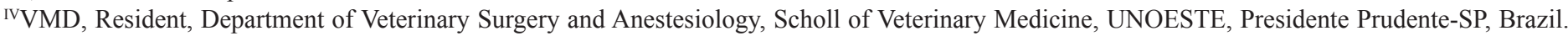 \\ Acquisition and interpretation of data, technical procedures.
}

\section{ABSTRACT}

PURPOSE: To investigate the sedative and clinical effects of the pharmacopuncture with xylazine, compared to the conventional dose of a intramuscular injection in dogs.

METHODS: Twelve dogs were randomly distributed in two groups of six animals and treated as follows: control group (X-IM): $1 \mathrm{mg}$ $\mathrm{kg}^{-1}$ of xylazine given intramuscularly (IM); pharmacopuncture group (X-Yintang): $0.1 \mathrm{mg} \mathrm{kg}^{-1}$ of xylazine diluted to $0.5 \mathrm{~mL}$ of saline injected into the Yin Tang acupoint. Heart rate, cardiac rhythm (ECG), systolic arterial blood pressure (SABP), respiratory rate (RR), rectal temperature (RT), blood glucose concentration, degree of sedation and adverse effects were evaluated.

RESULTS: Sedative effect was observed in both groups. The degree of sedation was greater in X-IM only at 15 min when compared with X-Yintang group. Cardiovascular established was observed in X-Yintang group, while marked reduction in the HR and increased incidence of ECG abnormalities were detected in X-IM. In both treatment groups, minimal changes were observed in relation to SABP, RR, RT and blood glucose. High incidence (66\%) of vomiting was observed in X-IM, while this adverse effect was absent in X-Yintang. CONCLUSION: Pharmacopuncture with xylazine induced clinically relevant sedative effects in dogs, with the advantage of reduction of undesirable side effects associated with $\alpha_{2}$-agonists, including bradycardia, cardiac arrhythmias, and emesis.

Key words: Acupuncture. Sedation. Anxiolytic Agents. Xylazine. Dogs. 


\section{Introduction}

Alpha ${ }_{2}$ adrenoreceptor agonists ( $\alpha_{2}$-agonists) have several characteristics that make them attractive as premedication for general anesthesia. These include sedation, anxiolysis, analgesia, prevention of autonomic reflex response, reduced anesthetic requirements, improved intraoperative stability and facilitation of induction of anesthesia ${ }^{1-3}$.

Xylazine $^{4,5}$, romifidine ${ }^{6,7}$, medetomidine ${ }^{8,9}$ and dexmedetomidine ${ }^{10,11}$ have all been used in dogs for sedation and anesthetic premedication. However, $\alpha_{2}$-agonists, through stimulation of central and peripheral adrenoreceptors, significantly affect cardiovascular function, which becomes most significant in sick, unstable, or cardiovascular compromised patients ${ }^{1-3}$. The main negative cardiovascular effects of all $\alpha_{2}$-agonists include bradycardia and associated arrhythmias (1st and 2nd degree atrioventricular heart block), a dramatic reduction in cardiac output by up to $50 \%$, and an increase in systemic vascular resistance (SVR) ${ }^{3,4}$.

The hemodynamic effects are typically dose related with the administration of $\alpha_{2}$-agonists. Lower doses of these drugs may be associated with more predominant central nervous system (CNS) effects, whereas higher doses probably cause a more pronounced stimulation of peripheral adrenoreceptors and vasoconstriction ${ }^{1,4}$.

Pharmacopuncture, the injection of subclinical doses of drugs into acupoints, has been proved to be a very successful practice in domestic animals ${ }^{12-14}$. A micro-dose of acepromazine (1/10 of the conventional dose) injected into the Yin Tang acupoint in dogs reduced in $32 \%$ the dose of thiopentone for induction of anaesthesia compared to $51 \%$ in animals treated with the full dose administered subcutaneously. These data suggest an improvement of the sedative effect produced by acepromazine when administrated into the Yintang acupoint ${ }^{12}$.

According to Traditional Chinese Medicine, the acupoint Yin Tang has a sedative effect in humans and animals ${ }^{15-18}$. In people, acupressure and manual acupuncture on the Yin Tang point was associated with pronounced changes in the bispectral index (BIS) values, with significant sedative effect ${ }^{17,18}$.

The aim of this study was to investigate the sedative and clinical effects of the pharmacopuncture with xylazine (1/10 of the dose), compared to the conventional dose of an intramuscular injection in dogs.

\section{Methods}

This study was approved by the Institutional Animal Research Ethical Committee (protocol number 563/10).
Twelve mixed breed dogs, weighting $10 \pm 2 \mathrm{~kg}$ were evaluated in this study. Health status was established on the basis of a physical examination and normal complete blood count, biochemistry perfil and electrocardiogram using standard methods.

After withdrawal of food and water for 12 and 3 hours, respectively, the dogs were randomly assigned to receive one of the following two treatments, in a double-blind design: the control group (X-IM) received $1 \mathrm{mg} \mathrm{kg}^{-1}$ intramuscular (IM) xylazine (Rompum, Bayer do Brazil, São Paulo, Brazil) and pharmacopuncture group (X-Yintang) received $0.1 \mathrm{mg} \mathrm{kg}^{-1}$ of xylazine diluted to $0.5 \mathrm{~mL}$ of saline solution injected into the Yin Tang acupoint, located on the dorsal midline of the head between the eyebrows (Figure 1).

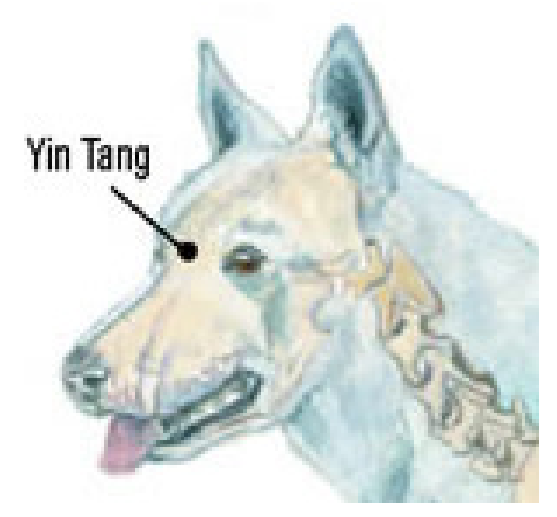

FIGURE 1 - Location of Yin Tang acupoint in dogs. Available from: http://www.animalacupressure.com/page.aspx?id=193

The following measurements were performed: Heart rate (HR) and rhythm (ECG) were monitored using a cardiac monitor (TEB, ECG, São Paulo, Brazil); systolic arterial blood pressure (SABP) was measured by noninvasive method using a Doppler ultrasonic (Doppler 841-A, Parks Medical Electronics, Las Vegas, EUA), adapting the cuff around the radius; respiratory rate (RR) was measured by the observation of thoracic movements for one minute; rectal temperature (RT), using a digital thermometer (BD, Minas Gerais, Brazil). HR, ECG, SABP and RT measurements were made before and every $15 \mathrm{~min}$ for $60 \mathrm{~min}$ after injection of the treatments.

Venous blood samples were collected from the cephalic vein to measure of glucose prior xylazine administration and after 30, and $60 \mathrm{~min}$. Blood samples for glucose measurements were immediately analyzed by amperometry in a portable glucometer (Accu-Check Aviva - Roche Diagnostics Corp. - Indianapolis-IN, USA).

The degree of sedation was scored on a 5-point scale as follows: alert $(0)=$ no motor deficits, equivalent to prebaseline; faint sedation (1) = stands, walks, some ataxia and disorientation; light sedation $(2)=$ stands but ataxic, can remain sternal; mild sedation (3) = cannot stand, can remain sternal, may struggle; moderate sedation (4) = can raise head, usually laterally 
recumbent; heavy sedation $(5)=$ nonresponsive, cannot raise head $^{8}$. Measurements were performed before and at 15, 30, 45, and 60 min after drug injection.

Data are collected by a single investigator who was blinded to the treatments throughout the experiment, following the same order (degree of sedation, cardiopulmonary parameters, rectal temperature and blood samples collection).

The data were analyzed using Graphpad software. Main effects of treatment or time within each treatment group were evaluated using analysis of variance for repeated measures. In analyses that demonstrated a significant main effect, pairwise comparisons of the appropriate means were made using Tukey's method for multiple pairwise comparisons. For sedation score, the
Mann-Whitney test was applied. In all tests, statistical significance was assigned to $\mathrm{p}<0.05$.

\section{Results}

At baseline, there were no significant differences between the two groups in HH, ECG, SABP, RR, RT, blood glucose and sedation score.

Xylazine IM significantly decreased the heart rate. The lowest heart rate was 40 beats per minute and it occurred from 30 to 45 min post-xylazine injection (X-IM). Five of six X-IM dogs showed bradyarrhythmia, whereas in X-Yintang treatment group, bradyarrhythmia was not observed (Table 1).

TABLE 1 - Heart rate (HR), respiratory rate (RR), systolic arterial blood pressure (SABP), rectal temperature (RT) and blood glucose in dogs treated with xylazine $\left(1 \mathrm{mg} \mathrm{kg}^{-1}\right)$ injected intramuscularly $(\mathrm{X}-\mathrm{IM}, \mathrm{n}=6)$ and xylazine $\left(0.1 \mathrm{mg} \mathrm{kg}^{-1}\right)$ injected into Yintang acupoint $(\mathrm{X}$-Yintang, $\mathrm{n}=6)$.

\begin{tabular}{|c|c|c|c|c|c|}
\hline \multirow{2}{*}{ Variable } & \multicolumn{5}{|c|}{ Time after xylazine injection (min) } \\
\hline & Baseline & 15 & 30 & 45 & 60 \\
\hline \multicolumn{6}{|c|}{ HR (beats $\min ^{-1}$ ) } \\
\hline X-IM & $112 \pm 26$ & $52 \pm 7 * \#$ & $51 \pm 11 * \#$ & $54 \pm 11^{* \#}$ & $60 \pm 15^{* \#}$ \\
\hline $\mathrm{X}$-Yintang & $99 \pm 17$ & $86 \pm 15$ & $81 \pm 10$ & $86 \pm 10$ & $91 \pm 10$ \\
\hline \multicolumn{6}{|c|}{ RR (breats $\min ^{-1}$ ) } \\
\hline X-IM & $38 \pm 16$ & $18 \pm 7$ & $15 \pm 8^{*}$ & $13 \pm 5^{*}$ & $12 \pm 2 *$ \\
\hline X-Yintang & $27 \pm 8$ & $24 \pm 6$ & $20 \pm 3$ & $18 \pm 3 *$ & $19 \pm 3 *$ \\
\hline \multicolumn{6}{|c|}{$\mathrm{SABP}(\mathrm{mmHg})$} \\
\hline X-IM & $115 \pm 8$ & $106 \pm 14$ & $91 \pm 3 * \#$ & $94 \pm 5^{\#}$ & $100 \pm 12$ \\
\hline X-Yintang & $123 \pm 10$ & $120 \pm 12$ & $113 \pm 5$ & $118 \pm 10$ & $117 \pm 10$ \\
\hline \multicolumn{6}{|l|}{$\mathrm{RT}\left({ }^{\circ} \mathrm{C}\right)$} \\
\hline X-IM & $38 \pm 0.2$ & $38 \pm 0.2$ & $38 \pm 0.5$ & $37 \pm 0.5^{* \#}$ & $37 \pm 0.7 * \#$ \\
\hline X-Yintang & $38.5 \pm 0.4$ & $38 \pm 0.3$ & $38 \pm 0.2$ & $38 \pm 0.2$ & $38 \pm 0.2$ \\
\hline \multicolumn{6}{|c|}{ Glucose $\left(\mathrm{mg} \mathrm{mL}^{-1}\right)$} \\
\hline X-IM & $80 \pm 6$ & ------ & $84 \pm 9$ & ------- & $92 \pm 12^{\#}$ \\
\hline X-Yintang & $78 \pm 9$ & ------ & $81 \pm 10$ & ------- & $75 \pm 9$ \\
\hline
\end{tabular}

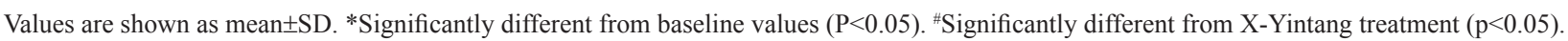

In addition, a higher incidence of ECG abnormalities (sinus arrest, first degree AV block, second degree AV block) were observed in X-IM group (Table 2).

The systolic arterial blood pressure did not change between treatment groups, except from 30 to $45 \mathrm{~min}$, when this parameter was lower in X-IM group in comparison with X-Yintang group (Table 1). In X-IM group, SABP was significantly lower at $30 \mathrm{~min}$ after xylazine administration when compared with the baseline values (Table 1).
TABLE 2 - Cardiac arrhythmias observed in dogs treated with xylazine $\left(1 \mathrm{mg} \mathrm{kg}^{-1}\right)$ injected intramuscularly $(\mathrm{X}-\mathrm{IM}, \mathrm{n}=6)$ and xylazine $\left(0.1 \mathrm{mg} \mathrm{kg}^{-1}\right)$ injected into Yintang acupoint (X-Yintang, $\left.\mathrm{n}=6\right)$.

\begin{tabular}{lccc}
\hline \multirow{2}{*}{ Groups } & \multicolumn{3}{c}{ Cardiac arrythmias\# } \\
\cline { 2 - 4 } & SA & $\begin{array}{c}\text { 1st degree AV } \\
\text { heart block }\end{array}$ & $\begin{array}{c}\text { 2nd degree AV } \\
\text { heart block }\end{array}$ \\
X-IM & $5 / 6$ & $3 / 6$ & $1 / 6$ \\
X-Yintang & ---- & ---- & ---- \\
\hline
\end{tabular}

${ }^{\#} \mathrm{~N}^{\circ}$ of dogs showing arrhythmia/ $\mathrm{N}^{\circ}$ of dogs evaluated. 
Respiratory rates were not significantly different between the treatment groups at any time point. However, lower RR was observed from 30 to 60 min after the drug injection, when compared with the baseline values in both groups (Table 1).

Rectal temperature was lower from 45 to $60 \mathrm{~min}$ in X-IM treatment group when compared with X-Yintang treatment group.

Minimal changes were observed in blood glucose concentration. Dogs from the X-IM group had blood glucose significantly higher than dogs from the X-Yintang group only at 60 min after xylazine injection (Table 1).

Vomiting was observed in four of the six dogs in X-IM (66.6\%), while no vomiting occurred in X-Yintang group.

The change in sedation scores following treatment administration was significantly different from baseline in both treatment groups. The greatest score sedation was observed at 15 and $30 \mathrm{~min}$, respectively in X-IM and X-Yintang groups. The level of sedation tended to be higher in X-IM group than in X-Yintang group, but this difference was significantly only at $15 \mathrm{~min}$ after xylazine injection (Figure 2).

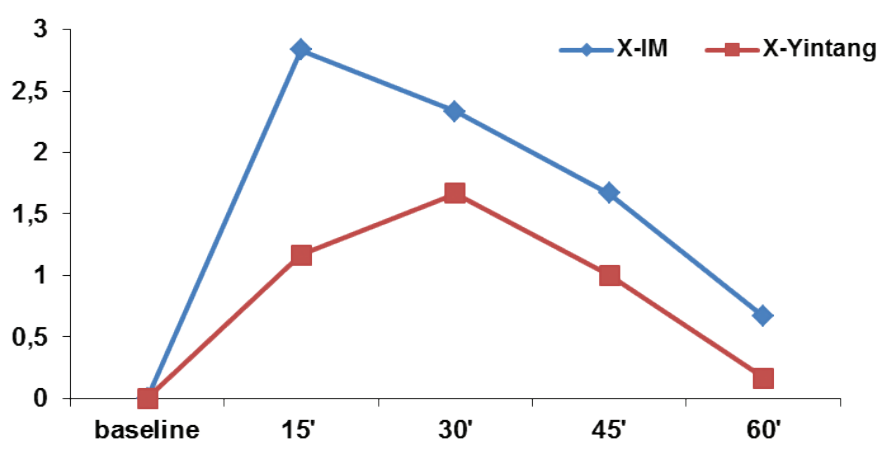

FIGURE 2 - Median sedation scores in dogs treated with xylazine (1mg $\left.\mathrm{kg}^{-1}\right)$ injected intramuscularly $(\mathrm{X}-\mathrm{IM}, \mathrm{n}=6)$ and xylazine $\left(0.1 \mathrm{mg} \mathrm{kg} \mathrm{kg}^{-1}\right)$ injected into Yin Tang acupoint (X-Yintang, $n=6)$. * Significantly different from baseline values $(\mathrm{p}<0.05)$. "Significantly different from $\mathrm{X}$-Yintang treatment $(\mathrm{p}<0.05)$. Times listed are 15, 30, 45 and 60 minutes following xylazine injection

\section{Discussion}

Despite the desirable clinical properties of the $\alpha_{2}$-agonists, the main limiting factor of their use is the adverse cardiovascular effect $^{1-3}$. Marked decreases in heart rate and cardiac output, increases in total vascular resistance, and transient changes in blood pressure, are expected dose-dependent effects of xylazine ${ }^{1,2}$.

It is well-established that administering xylazine consistently produces bradycardia ${ }^{1,4,5}$, and the results of the current study support this finding. As expected, the majority of the dogs in the X-IM group showed bradycardia $(\mathrm{HR}<60 \mathrm{bpm})$, while this effect was not evidenced in the X-Yintang group. This find confirms the dose-dependent cardiovascular depression induced by xylazine ${ }^{2}$. In addition, sinus arrest, first and second degree AV block occurred only in X-IM treated dogs. Sinus and AV block induced by $\alpha_{2}$-agonists are often associated with bradycardia and attributed to decreased sympathetic outflow from the central nervous system and increased vagal tone ${ }^{3}$.

Several studies have shown that arterial blood pressure has a biphasic response when $\alpha_{2}$-agonists drugs are administered ${ }^{7,8}$. In this study, we did not observe an initial increase in SABP in either of the groups. This result supports the findings of Monteiro et al..$^{5}$ following xylazine IM injection at a dose of 0.5 and $1 \mathrm{mg}$ $\mathrm{kg}^{-1}$ in dogs. The characteristics of the blood pressure changes appear to be in part determined by dose. Higher doses cause longer duration hypertension associated with a persistent increase in $\mathrm{SVR}^{2,3}$. At lower doses, central effects predominate and blood pressure decreases to pre-treatment or below pre-treatment values $^{6,19}$. Furthermore, another studies have shown that arterial blood pressure has a biphasic response observed after intravenous administration, but not after intramuscular administration ${ }^{4,19}$. In our study, arterial pressure decreased after xylazine treatment in both groups, which may be attributed to the sedative effect induced by $\alpha_{2}$-agonists drugs. Additionally, in X-IM group this effect may have been increased by the bradycardia ${ }^{8}$.

Xylazine has little effect on pulmonary function when administered at clinical doses. However, transient dose-dependent decreases in respiratory rate have also been reported ${ }^{1,2,19}$. In our study, although median RR decreased significantly in both treatment groups, the decrease was unlikely to be clinically relevant, which is in agreement with other studies in $\operatorname{dogs}^{5,20}$.

Previous studies have reported a decrease in body temperature in dogs given $\alpha_{2}$-agonists ${ }^{5,7}$. This effect is thought to result from decreased heat production secondary to muscle relaxation or from a direct effect of the drug within the thermoregulatory system ${ }^{19}$. In the present study, despite mild reduction in the rectal temperatures, body temperatures remained within clinically acceptable limits in both groups.

Transient hyperglycemia have been reported in several species sedated with xylazine or that are anesthetized using a regime that incorporates xylazine ${ }^{21,22}$. Blood glucose values tended to be higher in X-IM than X-Yintang, although significant difference was observed only at $60 \mathrm{~min}$ after xylazine injection. This result is in agreement with early studies that showed increased glucose values dose-dependently following xylazine treatment ${ }^{23,24}$.

Vomiting has previously been reported following the administration of xylazine to $\operatorname{dog}^{2,5}$. Alpha ${ }_{2}$-agonists typically 
induce vomiting by stimulating the chemoreceptor trigger zone, which is in close proximity to the locus coeruleus in the brain ${ }^{1,2}$. Xylazine induces vomiting during early sedation in as many as $50 \%$ of dogs and $90 \%$ of cats ${ }^{3}$. In the present study, the prevalence of vomiting in dogs which received xylazine IM was nearly $66 \%$, whereas in Yin Tang xylazine treated dogs, the prevalence of vomiting was reduced to $0 \%$ and this might be attributable to the low dose used in this treatment group. These finds support the effect of pharmacopuncture to enhance the effect of subclinical doses of drugs, with the advantage of reduction of undesirable side effects, as described by Luna et al. ${ }^{13}$.

Based on the sedation score, mild to moderate sedation was produced in the X-IM group, with the maximal sedative effect observed at $15 \mathrm{~min}$ following xylazine injection. As expected, sedation started quickly due the fast activation of the presynaptic $\alpha_{2}$ receptors ${ }^{1,2}$. Xylazine is rapidly absorbed after IM injection, resulting in maximum plasma concentration after $15 \mathrm{~min}^{25}$. On the order hand, 1/10 of the dose of xylazine in the Yin Tang acupoint induced slight to mild sedation, with the maximal sedative effect observed at $30 \mathrm{~min}$ after injection. The slow onset in X-Yintang group was expected, because the administration in an acupoint results in a subcutaneous absorption ${ }^{12}$.

The sedative effect established in X-Yintang treatment group is consistent with previous reports, showing the potentiation effect of subclinical doses of drugs injected in an acupoint, i.e. pharmacopuncture ${ }^{12-14}$. In horses, 1/10 of the dose of acepromazine at GV1 acupoint was able to maintain a certain degree of sedation at $60 \mathrm{~min}$, indicating a long-lasting effect of pharmacopuncture ${ }^{13}$.

Several acupoints may be used for analgesia in surgical procedures and also for sedation ${ }^{26-29}$. Kim and $\mathrm{Nam}^{28}$ showed sedative effect following an acupuncture application in the Yintang and GV20 acupoints in conscious dogs.

The mechanism by which acupuncture produces analgesia and sedation remains unclear. However, the opioid system and the adrenergic system have been considered to play important roles in mediating the effects of acupuncture ${ }^{30-32}$.

Recent studies have investigated the role of central norepinephrine (NE) in acupuncture ${ }^{33,34}$. It was reported that acupuncture reduced NE levels in certain brain areas as well as in the blood circulation ${ }^{35}$. Similarly, the sedative effect mediated by $\alpha_{2}$-agonists is linked with receptors located primarily in locus coeruleus neurons on the pons and lower brainstem ${ }^{36}$. Alpha2agonists bind with and intrinsically change the membranes of the $\alpha_{2}$-adrenoreceptors, preventing further release of the neurotransmitter NE. Centrally, NE is necessary for arousal. If the release of norepinephrine is blocked, the net result is sedation ${ }^{2,3}$.
In addition, previous studies have reported that the sedative effect of acupuncture may be reversed by the administration of a $\alpha_{2}$-adrenergic receptor antagonist, such as yohimbine ${ }^{36,37}$ or atipamezole ${ }^{32}$. Based on these finds, the sedative effect observed in the $\mathrm{X}$-Yintang group, may, at least in part, be attributed to the activation of the $\alpha_{2}$-adrenergic system induced by the acupoint stimulation mediated by the subclinical dose of xylazine administration.

\section{Conclusion}

Pharmacopuncture with xylazine induced clinically relevant sedative effects in dogs, with the advantage of reduction of undesirable side effects associated with $\alpha_{2}$-agonists, including bradycardia, arrhythmias, and emesis.

\section{References}

1. Tranquilli WJ, Maze M. Clinical pharmacology and use of $\mathrm{a}_{2}-$ adrenergic agonists in veterinary anaesthesia. Anaesth Pharmac Rev. 1993;1:297-309.

2. Paddleford RR, Harvey RC. Alpha 2 agonists and antagonists. Vet Clin North Am Small Anim Pract. 1999;29:737-45.

3. Sinclair MD. A review of the physiological effects of alpha2agonists related to the clinical use of medetomidine in small animal practice. Can Vet J. 2003;44:885-97.

4. Ilback NG, Stalhandske T. Cardiovascular effects of xylazine recorded with telemetry in the dog. J Vet Med A Physiol Pathol Clin Med. 2003;50:479-83.

5. Monteiro ER, Figueroa CD, Choma JC, Campagnol D, Bettini CM. Effects of methadone, alone or in combination with acepromazine or xylazine, on sedation and physiologic values in dogs. Vet Anaesth Analg. 2008;35:519-27.

6. Pypendop BH, Verstegen JP Cardiovascular effects of romifidine in dogs. Am J Vet Res. 2001;62:490-5.

7. Gómez-Villamandos RJ, Domínguez JM, Redondo JI, Martín EM, Granados MM, Ruiz I, Santisteban JM. Comparison of romifidine and medetomidine pre-medication in propofol-isoflurane anaesthetised dogs. J Vet Med A Physiol Pathol Clin Med. 2006;53:471-5.

8. Lamont LA, Burton SA, Caines D, Troncy ED. Effects of 2 different infusion rates of medetomidine on sedation score, cardiopulmonary parameters, and serum levels of medetomidine in healthy dogs. Can J Vet Res. 2012;76:308-16.

9. Guedes AG, Rude EP. Effects of pre-operative administration of medetomidine on plasma insulin and glucose concentrations in healthy dogs and dogs with insulinoma. Vet Anaesth Analg. 2013;40:472-81.

10. Congdon JM, Marquez M, Niyom S, Boscan P. Evaluation of the sedative and cardiovascular effects of intramuscular administration of dexmedetomidine with and without concurrent atropine administration in dogs. J Am Vet Med Assoc. 2011;239:81-9.

11. Rauser P, Pfeifr J, Proks P, Stehlík L. Effect of medetomidinebutorphanol and dexmedetomidine-butorphanol combinations on intraocular pressure in healthy dogs. Vet Anaesth Analg. 2012;39:301-5.

12. Luna SPL, Maiante AA, Xavier F, Osório DDP, Endo Y, Karasawa ASM. Efeito da acupuntura sobre a dose de indução anestésica do tiopental em cães. Rev Bras Ciênc Vet. 2002;9:292-4. 
13. Luna SP, Angeli AL, Ferreira CL, Lettry V, Scognamillo-Szabó M. Comparison of pharmacopuncture, aquapuncture and acepromazine for sedation of horses. Evid Based Complement Alternat Med. 2008;5:267-72.

14. Sousa NR, Luna SP, Cápua MLB, Lima AFM, Oliveira FA, Viveiros BM, Barbosa L. Analgesia da farmacopuntura com meloxicam ou da aquapuntura preemptivas em gatas submetidas à ovariosalpingohisterectomia. Ciênc Rural. 2012;42:1231-6.

15. Kim MS, Nam TC. Electroencephalography (EEG) spectral edge frequency for assessing the sedative effect of acupuncture in dogs. J Vet Med Sci. 2006;68:409-11.

16. Acar HV, Cuvaş O, Ceyhan A, Dikmen B. Acupuncture on Yintang point decreases preoperative anxiety. J Altern Complement Med. 2013;19:420-4.

17. Fassoulaki A, Paraskeva A, Patris K, Pourgiezi T, Kostopanagiotou G. Pressure applied on the extra 1 acupuncture point reduces bispectral index values and stress in volunteers. Anesth Analg. 2003;96:885-90.

18. Litscher G. Effects of acupressure, manual acupuncture and Laserneedle acupuncture on EEG bispectral index and spectral edge frequency in healthy volunteers. Eur J Anaesthesiol. 2004;21:13-9.

19. Greene SA., Thurmon JC. Xylazine: a review of its pharmacology and use in veterinary medicine. J Vet Pharmacol Ther. 1988;11:295-313.

20. Haskins SC, Patz JD, Farver TB. Xylazine and xylazine-ketamine in dogs. Am J Vet Res. 1986;47:636-41.

21. Changmin H, Jianguo C, Dongming L, Guohong L, Mingxing D. Effects of xylazole alone and in combination with ketamine on the metabolic and neurohumoral responses in healthy dogs. Vet Anaesth Analg. 2010;37:322-8.

22. Hsu WH. Yohimbine increases plasma insulin concentrations and reverses xylazine-induced hypoinsulinemia in dogs. Am J Vet Res. 1988;49:242-4.

23. DiTullio NW, Cieslinski L, Matthews WD, Storer B. Mechanisms involved in the hyperglycemic response induced by clonidine and other alpha-2 adrenoceptor agonists. J Pharmacol Exp Ther. 1984;228:168-73.

24. Ambrisko TD, Hikasa Y. Neurohormonal and metabolic effects of medetomidine compared with xylazine in beagle dogs. Can J Vet Res. 2002;66:42-9.

25. Garcia-Villar R, Toutain RPL, Alvinerie M, Ruckebusch Y. The pharmacokinetics of xylazine hydrochloride: an interspecific study. J. Vet. Pharmacol. Ther. 1981;4:87-92.

26. Gakiya HH, Silva DA, Gomes J, Stevanin H, Cassu RN. Electroacupuncture versus morphine for the postoperative control pain in dogs. Acta Cir Bras. 2011;26:346-51.

27. Cassu RN, Silva DA, Genari Filho T, Stevanin H. Electroanalgesia for the postoperative control pain in dogs. Acta Cir Bras. 2012;27(1):43-8.

28. Kim MS, Soh KS, Nam TC, Seo KM, Litscher G. Evaluation of sedation on electroencephalographic spectral edge frequency 95 in dogs sedated by acupuncture at GV20 or Yintang and sedative combination. Acupunct Electrother Res. 2006;31:201-12.

29. Zhou YY, Wanner NJ, Xiao Y, Shi XZ, Jiang XH, Gu JG, Xu GY. Electroacupuncture alleviates stress-induced visceral hypersensitivity through an opioid system in rats. World $\mathrm{J}$ Gastroenterol. 2012;18:7201-11.
30. Erthal V, da Silva MD, Cidral-Filho FJ, Santos AR, Nohama P. ST36 laser acupuncture reduces pain-related behavior in rats: involvement of the opioidergic and serotonergic systems. Lasers Med Sci. 2013 Jan 5. [Epub ahead of print]

31. Ishikawa S, Suga H, Fukushima M, Yoshida A, Yoshida Y, Sunagawa M, Hisamitsu T. Blood fluidity enhancement by electrical acupuncture stimulation is related to an adrenergic mechanism. J Acupunct Meridian Stud. 2012;5:21-8.

32. Kim MS, Seo KM. Effects of atipamezole and naloxone on electroencephalographic spectral edge frequency 95 in dogs sedated by acupuncture at GV20 and Yintang point. J Vet Med Sci. 2007;69:577-9.

33. Li M, Hu L, Cai RL, Wu ZJ, Wang KM. Effects of electroacupuncture at PC6 and BL15 on nerve electrical activity in spinal dorsal root and norepinephrine and dopamine contents in paraventricular nucleus of hypothalamus in rats with acute myocardial ischemia. Zhong Xi Yi Jie He Xue Bao. 2012;10:874-9.

34. Zhang Y, Zhang RX, Zhang M, Shen XY, Li A, Xin J, Ren K, Berman BM, Tan M, Lao L. Electroacupuncture inhibition of hyperalgesia in an inflammatory pain rat model: involvement of distinct spinal serotonin and norepinephrine receptor subtypes. Br J Anaesth. 2012;109:245-52.

35. Cao XD, Xu SF, Lu WX. Inhibition of sympathetic nervous system by acupuncture. Acupunct Electrother Res. 1983;8:25-35.

36. De Sarro GB, Ascioti C, Froio F, Libri V, Nistico G. Evidence that locus coeruleus is the site where clonidine and drugs acting at $\alpha 1$ and $\alpha 2$-adrenoceptors affect sleep and arousal mechanisms. Br J Pharmacol. 1987;90:675-85.

37. Chen M, Zhuang W, Huang X. The inhibition of yohimbine injected intrathecally on electroacupuncture-induced analgesia and release of beta-endorphin from rat brain. Zhen Ci Yan Jiu. 1996;21:52-5.

\section{Correspondence:}

\section{Renata Navarro Cassu}

Faculdade de Medicina Veterinária e Ciência Animal-UNOESTE Departamento Cirurgia Veterinária e Anestesiologia

19067-175 Presidente Prudente - SP Brasil

Tel.: (55 18)3229-2077

navarro@unoeste.br renavarro@uol.com.br

Received: Sept 17, 2013

Review: Nov 18, 2013

Accepted: Dec 20, 2013

Conflict of interest: none

Financial source: none

${ }^{1}$ Research performed at Veterinary Hospital, Department of Veterinary Surgery and Anestesiology, Faculty of Veterinary Medicine, Oeste Paulista University (UNOESTE), Presidente Prudente-SP, Brazil. 